\title{
Early-Stage Retinal Melatonin Synthesis Impairment in Streptozotocin-Induced Diabetic Wistar Rats
}

\author{
Daniella do Carmo Buonfiglio, ${ }^{1}$ Rodrigo Antonio Peliciari-Garcia, ${ }^{1}$ \\ Fernanda Gaspar do Amaral, ${ }^{1}$ Rafael Peres, ${ }^{1}$ Tatiane C. Araujo Nogueira, ${ }^{1}$ \\ Solange Castro Afeche, ${ }^{2}$ and José Cipolla-Neto ${ }^{1}$
}

Purpose. Retinal melatonin synthesis occurs in the photoreceptor layer in a circadian manner, controlling several physiologic rhythmic phenomena, besides being the most powerful natural free radical scavenger. The purpose of the present work was to evaluate the diurnal profile of retinal melatonin content and the regulation of its synthesis in the retina of streptozotocininduced diabetic rats.

Methods. Diabetes was induced in male Wistar rats (12 hour-12 hour light/dark cycle) with streptozotocin. Control, diabetic, and insulin-treated diabetic animals were killed every 3 hours throughout the light-dark cycle. Retinal melatonin content was measured by high-performance liquid chromatography, arylalkylamine $N$-acetyltransferase (AANAT) activity was analyzed by radiometric assay, Bmal1 gene expression was determined by qPCR, and cyclic adenosine monophosphate (cAMP) content was assessed by ELISA.

RESULTS. Control animals showed a clear retinal melatonin and AANAT activity daily rhythm, with high levels in the dark. Diabetic rats had both parameters reduced, and the impairment was prevented by immediate insulin treatment. In addition, the Bmal1 expression profile was lost in the diabetic group, and the retinal cAMP level was reduced 6 hours after lights on and 3 hours after lights off.

Conclusions. The present work shows a melatonin synthesis reduction in diabetic rats retinas associated with a reduction in AANAT activity that was prevented by insulin treatment. The Bmal1-flattened gene expression and the cAMP reduction seem to be responsible for the AANAT activity decrease in diabetic animals. The melatonin synthesis reduction observed in the pineal gland of diabetic rats is also observed in a local melatonin tissue synthesizer, the retina. (Invest Ophthalmol Vis Sci. 2011;52:7416-7422) DOI:10.1167/iovs.10-6756

M elatonin ( $N$-acetyl-5-methoxytryptamine), synthesized mainly by the pineal gland, is also produced in the retina of several vertebrate species. Retinal melatonin synthesis occurs in a subpopulation of photoreceptors ${ }^{1}$ and, as observed in

From the ${ }^{1}$ Department of Physiology and Biophysics, Institute of Biomedical Sciences, University of São Paulo, São Paulo, Brazil; and the ${ }^{2}$ Laboratory of Pharmacology, Butantan Institute, São Paulo, Brazil.

Supported by the Sao Paulo State Research Foundation (FAPESP), Grants 04/06767-2 and 09/52920-0 and by Fellowship 141071/2005-2 from CNPq.

Submitted for publication October 20, 2010; revised March 16 , July 19, July 26, and July 29, 2011; accepted August 1, 2011.

Disclosure: D. do Carmo Buonfiglio, None; R.A. PeliciariGarcia, None; F.G. Amaral, None; R. Peres, None; T.C. Araujo Nogueira, None; $\mathbf{S}$. Castro Afeche, None; J. Cipolla-Neto, None

Corresponding author: José Cipolla-Neto, Department of Physiology and Biophysics, University of São Paulo, Av. Prof. Lineu Prestes, 1524, São Paulo, SP, CEP 05508-900, Brazil; cipolla@icb.usp.br. the pineal gland, shows a clear daily variation with low levels during the light period and high levels at night. ${ }^{2}$ Results of previous studies have demonstrated that melatonin synthesis pathway enzymes are under circadian control, at either transcriptional or posttranscriptional levels in several species. ${ }^{3-7}$

ArylalKylamine $N$-acetyltransferase (AANAT) is the main regulatory enzyme in melatonin synthesis and both its mRNA level and activity show a marked circadian variation in rat retina. ${ }^{5,8,9}$ The AANAT regulation is under the light-dark cycle and circadian control. During the dark, increased intracellular cyclic adenosine monophosphate (cAMP) stimulates Aanat gene expression through protein kinase A (PKA) activation and cAMP response element-binding (CREB) phosphorylation and its interaction with cAMP response element (CRE) in the Aanat promoter. ${ }^{10}$ Besides that, increased CAMP and PKA activity phosphorylate AANAT and promote its binding to $14-3-3$ protein, possibly protecting it from proteolysis. ${ }^{11}$ The clock mechanism controls the rhythmic expression of Aanat mRNA by the interaction of the BMAL1:CLOCK complex with the E-box present in the Aanat promoter. ${ }^{12}$ The circadian clock also works as a gate, regulating rhythmic adenylyl cyclase (AC1) mRNA expression and controlling the period during the day when cAMP levels are maximally stimulated. In this way, melatonin synthesis is exclusively gated to the night, by increased $\mathrm{Ca}^{2+}$ influx and stimulation of cAMP synthesis late in the day and at night, when AC1 protein expression is high, but not during the early morning. ${ }^{8}$

Several retinal physiologic phenomena were described as rhythmic, including rod disc shedding, ${ }^{13}$ visual sensitivity, ${ }^{14}$ melatonin release in vivo ${ }^{2}$ and in vitro, ${ }^{1}$ dopamine synthesis, ${ }^{15}$ electroretinogram b-wave amplitude, ${ }^{16}$ extracellular $\mathrm{pH},{ }^{17}$ and intraocular pressure. ${ }^{18}$ In addition, most retinal rhythms are partially modulated by rhythmic melatonin and dopamine release. $^{19-22}$

Melatonin is one of the most powerful natural free radical scavengers, ${ }^{23}$ preventing oxidative damage to macromolecules, including lipids, proteins, and nucleic acids. ${ }^{24,25}$ Gül et al. ${ }^{26}$ have shown that melatonin reduces corneal injury in a streptozotocin (STZ)-induced diabetic rat model. In an induced ischemia model, melatonin blocks apoptosis in cultured human retinal pigment epithelium (RPE) cells. ${ }^{27}$ In addition to the potent antioxidant property of melatonin by itself, some of its metabolites are themselves direct free radical scavengers, ${ }^{28,29}$ increasing melatonin's antioxidant capacity. Besides that, melatonin stimulates several antioxidant enzymes, including superoxide dismutase and glutathione peroxidase. ${ }^{25,30}$

In diabetes mellitus, the hyperglycemia increases the enzymatic conversion of glucose to polyalcohol sorbitol, with concomitant nicotinamide adenine dinucleotide phosphate (NADPH) and glutathione decrease, ${ }^{26}$ enhancing the oxidative stress that may be involved in the development of diabetic retinopathy. ${ }^{31}$ 
Considering the essential function of melatonin on retinal physiology and the functional interrelationship between insulin and melatonin, ${ }^{32-35}$ we investigated the diurnal profile of retinal melatonin content and AANAT activity in the retina of STZ-induced diabetic rats.

To the best of our knowledge, this is the first evidence of decreased melatonin production in retinas of STZ-induced diabetic rats.

\section{Materials ANd Methods}

\section{Animals}

Male Wistar rats weighing 240 to $280 \mathrm{~g}$ were obtained from the Institute of Biomedical Sciences, University of São Paulo, São Paulo, Brazil. The animals were kept under a 12-hour:12-hour light- dark cycle (lights on at $6 \mathrm{AM}$; Zeitgeber Time [ZT]0), in a temperature-controlled room $\left(21 \pm 2^{\circ} \mathrm{C}\right)$, with food and water ad libitum. Ethics approval was granted for this study by the Committee of Ethics in Animal Experimentation of the Institute of Biomedical Sciences, University of São Paulo, and it is in compliance with the ARVO Statement for the Use of Animals in Ophthalmic and Vision Research.

\section{Experimental Design and STZ-Induced Diabetes}

Animals were divided into three groups: control, untreated diabetic, and insulin (INS)-treated diabetic group. Diabetes was induced by a single intraperitoneal injection of STZ ( $60 \mathrm{mg} / \mathrm{kg}$ body weight; SigmaAldrich, St. Louis, MO) freshly diluted in citrate buffer $(10 \mathrm{mM}, \mathrm{Na}$ citrate; $\mathrm{pH}$ 4.5). Nondiabetic control rats were injected with citrate buffer in the same volume. All the injections were performed during the daytime. Body weight and glycemia were measured before and after the STZ intraperitoneal injection. Tail blood was collected for glucose determination using a glucometer (Optium Xceed; Medisense, Abingdon, UK) after 24 hours of induction. Animals with glycemia $>200 \mathrm{mg} / \mathrm{dL}$ were considered diabetic and included in the experimental group. INS-treated diabetic animals received $2 \mathrm{U}$ subcutaneous long-action insulin (Glargina/Lantus; Sanofi-Aventis, Paris, France) in the beginning of the day and $2 \mathrm{U}$ regular insulin (Humulin R; Eli Lilly, Paris, France) plus 2 U long-acting insulin (Glargina/Lantus; SanofiAventis) in the beginning of the night. The treatment started 1 day after diabetes induction, and the protocol was modified from Freitas et al. ${ }^{36}$

The STZ-induced diabetic condition was well established in our rats, as can be evaluated by the high blood glucose concentrations observed in the induced animals. No significant difference was found between the INS-treated and control groups, showing that the insulin treatment was capable of restoring the blood glucose concentration to control levels (STZ-induced diabetic $361.7 \pm 76.78 \mathrm{mg} / \mathrm{dL}, n=49$ control $95.81 \pm 14.39 \mathrm{mg} / \mathrm{dL}, n=27$; and INS-treated $130.1 \pm 78.74$, $n=20$; one-way ANOVA, $P<0.0001$, STZ-induced diabetic versus control and INS-treated).

The effects of diabetes on retinal melatonin synthesis were evaluated 3 days after STZ or citrate buffer injection. Independent groups of control, STZ-induced diabetic and INS-treated diabetic animals were killed every 3 hours throughout the 24-hour light-dark cycle.

\section{Pinealectomy}

To verify whether circulating melatonin levels influence the amount of retinal melatonin we performed a pinealectomy (PINX), as previously described. ${ }^{37}$ Control and PINX animals were killed during the dark period at ZT12, $-15,-18,-21$, and -24 , at 30 days after surgery.

\section{Melatonin Levels Measurement}

Retinal melatonin levels were measured by high-performance liquid chromatography (HPLC) with electrochemical detection (Empower software; Waters, Milford, MA) ${ }^{38}$ Melatonin was separated on a C18 column $(5 \mu \mathrm{m}, 150 \times 3.9 \mathrm{~mm}$; Resolve; Waters). The chromatographic system was isocratically operated with the following mobile phase: 0.1 M sodium acetate, $0.1 \mathrm{M}$ citric acid, $0.15 \mathrm{mM}$ ethylene diamine triacetic

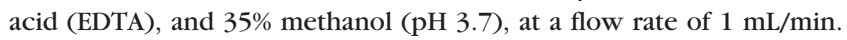
The electrochemical detector potential was adjusted to $+900 \mathrm{mV}$. The elution time for melatonin was approximately 6 minutes. Each retina was sonicated (Microson XL 2005; Heat System, Inc., Farmingdale, NY) in a solution of $0.1 \mathrm{M}$ perchloric acid $(120 \mu \mathrm{L})$, containing $0.02 \%$ EDTA and $0.02 \%$ sodium bisulfate. After centrifugation ( 2 minutes, 13,000g, Eppendorf 5415C Centrifuge; Brinkman Instruments Inc., Westbury, $\mathrm{NY}), 40 \mu \mathrm{L}$ of the supernatant was injected into the chromatographic system (model 7125 Injector, 20- $\mu$ L loop; Rheodyne Inc., San Francisco, CA)

\section{AANAT Activity Determination}

AANAT activity was measured by a radiometric assay. ${ }^{39,40}$ Briefly, 100 $\mu \mathrm{L}$ of $0.1 \mathrm{M}$ sodium phosphate buffer ( $\mathrm{pH} 6.8$ ), containing $40 \mathrm{mM}$ tryptamine and $[3 \mathrm{H}]$-acetyl coenzyme $\mathrm{A}(2 \mathrm{mM}$; final specific activity $=$ $4 \mathrm{mCi} / \mathrm{mmol}$; Sigma-Aldrich), was added to a microcentrifuge tube containing one retina kept at $4^{\circ} \mathrm{C}$. The retinas were sonicated and then incubated at $37^{\circ} \mathrm{C}$ for 20 minutes. The reaction product $N$ - $3[\mathrm{H}]$ acetyltriptamine was extracted with chloroform $(1 \mathrm{~mL})$. Samples of $500 \mu \mathrm{L}$ were evaporated until dry in a scintillation vial, and radioactivity was determined (Tri-Carb 2100 Packard $\beta$ counter; GMI Inc., Ramsey, MN).

\section{Cell Viability and DNA Fragmentation}

Retinas obtained from nondiabetic and diabetic rats killed by decapitation were dissected, transferred to a phosphate buffer solution, and incubated for 20 minutes at $37^{\circ} \mathrm{C}$ with $0.25 \%$ trypsin-EDTA (InvitrogenGibco, Grand Island, NY). Enzymatic digestion was stopped by the addition of Dulbecco's modified Eagle's medium (DMEM; Cultilab, Campinas, SP, Brazil) containing $10 \mathrm{IU} / \mathrm{mL}$ penicillin, $10 \mu \mathrm{g} / \mathrm{mL}$ streptomycin, $10 \%$ fetal bovine serum, $2 \mathrm{mM}$ glutamine, and $25 \mathrm{mM}$ glucose. Tissue was mechanically dissociated with a micropipette, and cells were evaluated as describe below.

TABLE 1. Primer Sequences for Rat Bmal1, Actb, Rp137 and Actg1, Real-Time Quantitative RT-PCR Assays

\begin{tabular}{|c|c|c|}
\hline Target and Reference Genes & RefSeq & Sequence \\
\hline Bmal 1 (Arntl) & NM_024362.2 & $\begin{array}{l}5^{\prime} \text { - CCGATGACGAACTGAAACACC - 3' } \\
5^{\prime}-\text { - TCTTCCCTCGGTCACATCCT - } 3^{\prime}\end{array}$ \\
\hline$A c t b$ & NM_031144 & $\begin{array}{l}\text { 5' - CTAGGAGCCAGGGCAGTAATCT - 3' } \\
5^{\prime} \text { - AAGACCTCTATGCCAACACAGTG - 3' }\end{array}$ \\
\hline Rpl37a & NM_001108801 & $\begin{array}{l}\text { 5' - CGCTAAGTACACTTGCTCCTTCTG - 3' } \\
\text { 5' - GCCACTGTTTTCATGCAGGAAC - 3' }\end{array}$ \\
\hline $\operatorname{Actg} 1$ & NM_001127449 & $\begin{array}{l}\text { 5' - TACCCTATTGAGCACGGCAT - 3' } \\
5^{\prime} \text { - CGCAGCTCGTTGTAGAAGGT - 3' }\end{array}$ \\
\hline
\end{tabular}

RefSeq is provided by the National Center for Biotechnology Information, Bethesda, MD (www.ncbi.nlm.nih.gov/locuslink/refseq/). 


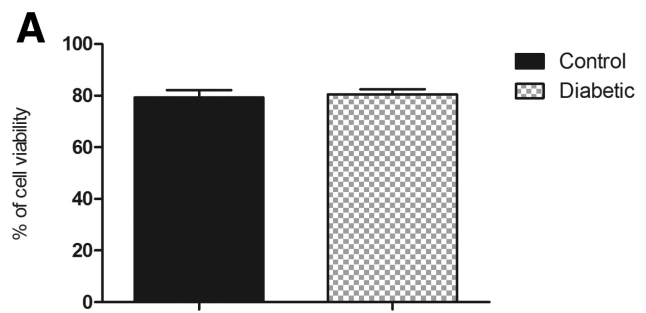

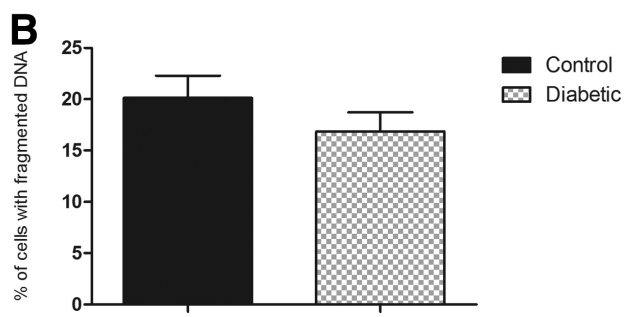

Figure 1. Cell viability (A) and DNA fragmentation (B) after 3 days of STZ-induced diabetes; $n=10$ control and $n=6$ diabetic animals, plotted as the mean \pm SEM.
Rat retina cells were washed and suspended in phosphate-buffered saline (PBS). Afterward, $50 \mu \mathrm{L}$ of propidium iodide solution $(50 \mathrm{mg} / \mathrm{mL}$ in PBS) was added, and the cells were analyzed with flow cytometry (FACSCalibur; BD Biosciences, San Jose, CA). Fluorescence was measured using the FL2 channel (orange-red fluorescence; 585/42 nm). Ten thousand events were analyzed per experiment. Cells with propidium iodide fluorescence were then evaluated (Cell Quest software; BD Biosciences). DNA fragmentation was calculated after DNA staining with propidium iodide according to a method previously described. ${ }^{41}$ The pellet was gently resuspended in $300 \mu \mathrm{L}$ hypotonic solution containing $50 \mathrm{mg} / \mathrm{mL}$ propidium iodide, $0.1 \%$ sodium citrate, and $0.1 \%$ Triton X-100. The cells were then incubated for 1 hour at room temperature. Fluorescence was measured and analyzed as described above.

\section{cAMP Immunoassay}

Retinas were homogenized in $0.1 \mathrm{M} \mathrm{HCl}$ using a homogenizer (Polytron; VWR International, Lutterworth, UK). After 5 minutes of centrifugation, the supernatants were collected and assayed directly according to the kit protocol (BioVision Research Products, Mountain View, CA).

\section{Real-Time Quantitative PCR}

Retinal total RNA was isolated using a guanidine isothiocyanate-based reagent (Trizol; Invitrogen Corp., Carlsbad, CA), according to the manufacturer's specifications. Total RNA was eluted in RNase-free water, treated with DNase genomic DNA remover (Turbo DNA-free; Ambion, Austin, TX) according to the manufacturer's specifications. Reverse transcriptase (200 U Superscript III; Invitrogen Corp.), DTT (10 nM), dNTP (10 mM each), RNase inhibitor ( $40 \mathrm{U})$, and random primers $(150 \mathrm{ng}$ ) were used to reverse transcribe $1 \mu \mathrm{g}$ of total RNA in a final reaction volume of $20 \mu \mathrm{L}$. qRT-PCR was performed (7500 Real-Time PCR System; Applied Biosystems, Inc. [ABI], Foster City, CA) with $25-\mu \mathrm{L}$ reactions containing $2 \mu \mathrm{L}$ of cDNA $(10 \mathrm{ng} / \mu \mathrm{L})$, SYBR green (Power SYBR Green; ABI), and $400 \mathrm{nM}$ specific intron-spanning primers (Table 1). The cycling parameters included an initial denaturation step at $95^{\circ} \mathrm{C}$ for 10 minutes, followed by 40 cycles of $95^{\circ} \mathrm{C}$ for 15 seconds and annealing and extension at $60^{\circ} \mathrm{C}$ for 1 minute. Melting curve analyses $(\mathrm{Tm})$ and ethidium bromide ( $\mathrm{EtBr})$-agarose gel $(2.2 \%$ $\mathrm{wt} / \mathrm{vol}$ ) electrophoresis of the amplified products were performed for product specificity assessment. A set of 10 -fold serial dilutions of each internal standard $\left(10^{1}-10^{7}\right.$ copies $\left./ 2 \mu \mathrm{L}\right)$ was used to generate a standard curve, and all qRT-PCR assays were linear within this concentration range with correlation coefficients $\left(r^{2}>0.999\right)$. Transcript numbers were determined by the system software (model 7500, ver. 2.0.3; $\mathrm{ABI})$ and normalized using the geometric mean calculated from the reference genes $A c t b, R p l 37 a$, and $A c t g 1$, which were indicated as the most suitable ones by the software GeNorm. ${ }^{42}$

\section{Statistics}

All the results were plotted as the mean \pm SEM. One-way ANOVA was used to evaluate the influence of the variable "time of day" on each temporal series, two-way ANOVA with Bonferroni's posttest was used to compare groups regarding the factors time of day, treatment (control, diabetic, and INS-treated), and the interaction between them Student's $t$-test was used when appropriate (all statistical tests and graphics: Prism, ver. 5.01 for Windows; GraphPad Software, San Diego, CA). Results are representative of at least two independent experimental blocks.

\section{Results}

\section{Cell Viability and DNA Fragmentation}

The flow cytometer results showed that 3 days of STZ-induced diabetes did not cause retinal cell necrosis (viability test) or retinal cell apoptosis (DNA fragmentation test) when compared to control group values (Fig. 1).

\section{Daily Retinal Melatonin Profile after 3 Days of STZ-Induced Diabetes}

As expected, retinas of the control animals showed a clear daily rhythm of melatonin synthesis, with high levels during the night and low levels during the day (Fig. 2). In the retinas of the diabetic rats, a nearly $40 \%$ reduced melatonin synthesis at ZT18 $(P<0.01)$ and ZT21 $(P<0.05)$ was observed compared with that of the control (Fig. 2). On the other hand, insulin treatment prevented melatonin reduction, since no statistical significance was found between the control and INS-treated diabetic animals after 3 days of treatment (Fig. 2).

\section{Retinal Melatonin from PINX and Intact Animals}

As can be observed in Figure 3, there was no difference in the retinal melatonin content of the PINX and intact animals. This finding leads us to conclude that pineal melatonin does not influence the amount of retinal melatonin in rats.

\section{Daily AANAT Activity Profile after 3 Days of STZ-Induced Diabetes}

In an attempt to investigate why retinal melatonin is reduced in diabetic rats, we analyzed the daily AANAT activity profile. The AANAT activity of the control group presented

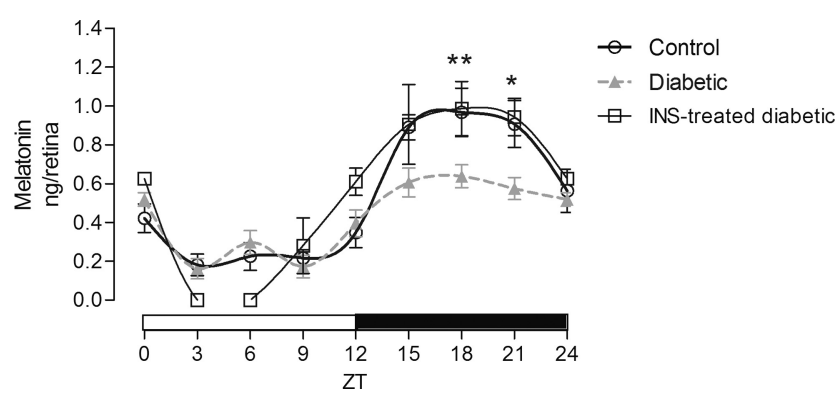

FIGURE 2. Daily retinal melatonin profile. Retinas were collected every 3 hours throughout the light-dark cycle after 3 days of STZinduced diabetes; $n=12$ control, $n=12$ diabetic, and $n=3$ INS-treated diabetic retinas per time point. Two-way ANOVA with Bonferroni's multiple-comparison posttest: $P<0.05$ for the treatment factor, $P<0.0001$ for the ZT factor, and $P<0.005$ for the interaction. ${ }^{* *} P<0.01{ }^{*} P<0.05$ vs. diabetic; plotted as the mean \pm SEM. 


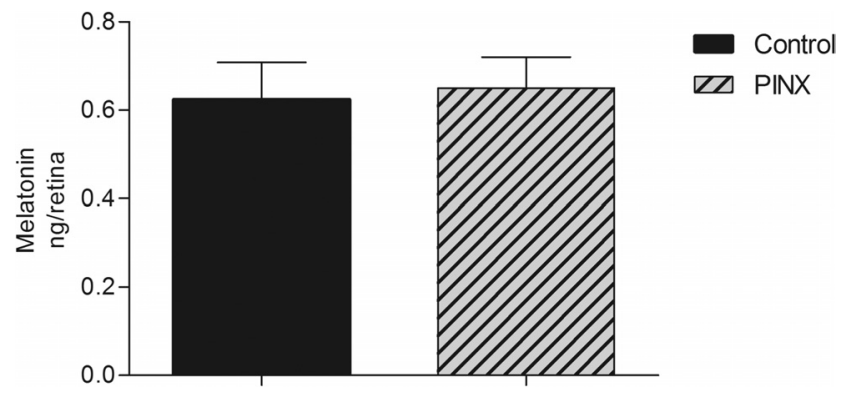

FigURE 3. Retinal melatonin from PINX and intact control animals; $n=16$ plotted as the mean \pm SEM.

higher values in the dark period at ZT15 $(P<0.01)$ and lower levels in the light period at ZT6 $(P<0.01)$ in comparison to that in the diabetic group (Fig. 4). On the other hand, the retinal AANAT activity daily fluctuation that was abolished in rats with STZ-induced diabetes was completely restored in the INS-treated group.

\section{Daily Retinal Bmal1 mRNA and cAMP Content after 3 Days of STZ-Induced Diabetes}

Bmal1 gene expression and cAMP content analysis were performed to elucidate the AANAT activity reduction observed in the diabetic group (Fig. 5).

Our data show Bmal1 that gene expression was high in the middle of the day (ZT6) and at ZT12, -15, and -18 in the control group. In the diabetic group, this pattern of expression vanished completely (Fig. 5A). The retinal cAMP level was significantly reduced at ZT6 $(P<0.001)$ and at ZT15 $(P<0.001)$ in the diabetic group, in comparison with that in the control group (Fig. 5B).

\section{Retinal Melatonin and AANAT Activity at ZT18 after 15 Days of STZ-Induced Diabetes}

To verify whether the reduction of retinal melatonin content and AANAT activity persists, we analyzed both parameters at ZT18 after 15 days of STZ-induced diabetes (Fig. 6). We observed a $75 \%$ reduction in the retinal melatonin content and a decrease in AANAT activity in the diabetic animals compared with that in the control animals after 15 days of induction.

\section{Discussion And Conclusions}

Several studies have shown the protective properties of melatonin in retinas of STZ-induced diabetic rats. ${ }^{24,26,43}$ Our work is the first to show the effects of STZ-induced diabetes on retinal melatonin synthesis.

In the present work, the STZ-induced diabetic condition was established in our rats and verified by high blood glucose concentrations and hypoinsulinemia (data not shown). The insulin treatment was capable of restoring the blood glucose concentration to control levels.

Initially, the cellular viability and DNA fragmentation of retinas from control and diabetic rats did not show any significant statistical difference, validating the study of retinal melatonin synthesis in the STZ-induced diabetes model. Park et al. $^{44}$ showed, in an STZ-induced diabetes model, degenerative changes from 1 week onward in postsynaptic processes of horizontal cells in the deep invaginations of the photoreceptor cell layer, where melatonin synthesis takes place. The same group reported photoreceptor cell apoptosis after 4 weeks of disease. Based on these studies, it is unlikely that a level of retinopathy is established after 3 days of diabetes that could affect the results that we obtained. However, we have to consider that flow cytometry does not specifically evaluate the photoreceptors, which are the melatonin-synthesizing cells.

The circadian profile of retinal melatonin content observed in the control group corroborates that found by Tosini and Menaker. ${ }^{1}$ On the other hand, we showed a $40 \%$ reduction on the nocturnal retinal melatonin content in the STZ-induced diabetic group in comparison to the control. Moreover, the reduction in the retinal AANAT activity corresponded to the reduced melatonin synthesis. In addition, when the animals had their diabetes treated by the administration of insulin, we found a complete reestablishment of both the melatonin synthesis profile and AANAT activity. Furthermore, we demonstrated a reduction in melatonin synthesis and AANAT activity 15 days after STZ induction.

There is no information in the literature about retinal melatonin synthesis in diabetic rats; the available data concern pineal melatonin synthesis in different diabetes models. In accordance with our results in the retina, some reports described a significant reduction of pineal melatonin synthesis in diabetic rats induced by alloxan or STZ (Amaral FG, personal communication, 2010) ${ }^{45,46}$ as well as in hamsters. ${ }^{47,48}$ Decreased plasma melatonin levels were found in type 1 diabetic patients, ${ }^{49,50}$ in type 2 diabetic patients, and in type 2 diabetic rats. $^{51}$

In an attempt to elucidate whether the reduced plasma melatonin content observed in diabetic rats would explain the reduced levels of retinal melatonin in our diabetic animals, we analyzed the retinal melatonin content in pinealectomized rats and compared it with that in control animals. No difference was found between the groups, so it is possible to conclude that the melatonin measured in the retina is exclusively of retinal origin. In this regard, the melatonin reduction found in the diabetic group retinas is most probably due to the impaired intrinsic mechanism of melatonin synthesis in the retina that led us to proceed with the analysis of retinal AANAT activity.

Considering the AANAT activity profile in the retinas, our results are in agreement with those of Niki et al., ${ }^{9}$ who demonstrated the circadian pattern of this enzyme activity. STZinduced diabetic rats showed a loss of AANAT activity rhythmicity, which was partially restored in INS-treated animals. Although insulin treatment did not totally recover the control AANAT activity pattern, the melatonin content results show that insulin reposition was able to recover not only the retinal melatonin level, but also the rhythmic pattern that is observed

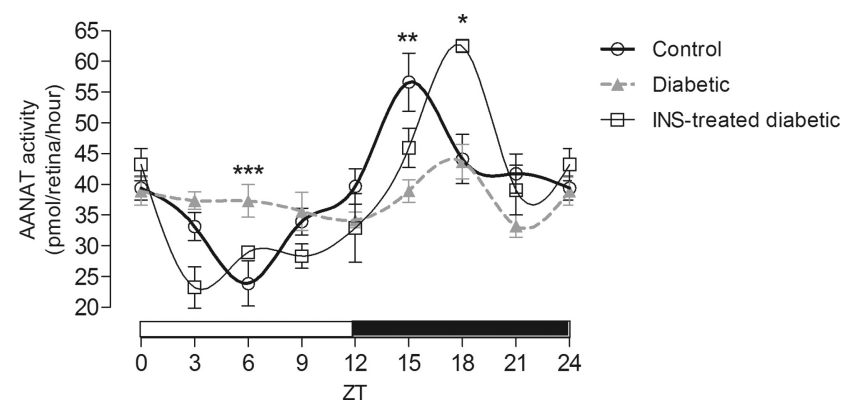

FIGURE 4. Daily retinal AANAT activity profile. Retinas were collected every 3 hours throughout the light-dark cycle after 3 days of STZinduced diabetes: $n=12$ control, $n=12$ diabetic, and $n=3$ INS-treated diabetic rat retinas per time point. Two-way ANOVA with Bonferroni's multiple-comparison posttest: $P=0.4360$ for the treatment factor, $P<0.0001$ for the ZT factor, and $P=0.0001$ for the interaction. ${ }^{* * *} P<0.001$ vs. control, ${ }^{* *} P<0.01$ vs. diabetic, ${ }^{*} P<0.05$ vs. control and diabetic, plotted as the mean \pm SEM. 
A

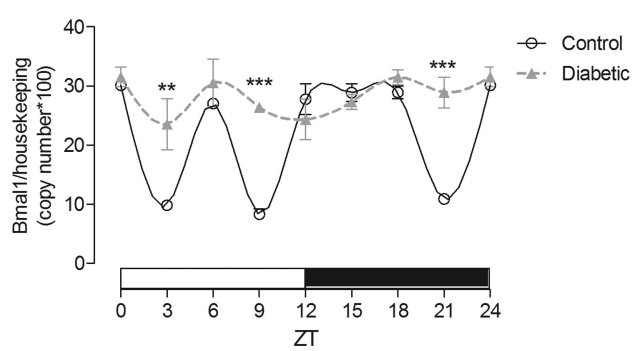

B

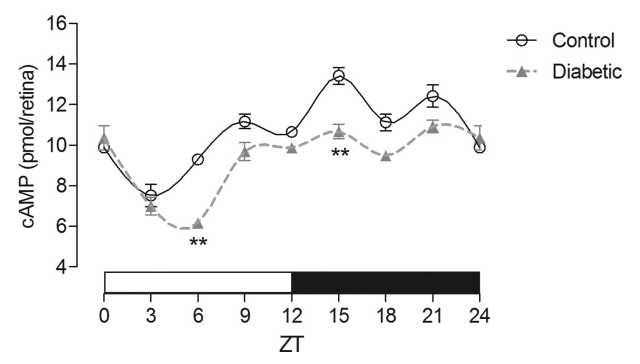

FIGURE 5. Daily retinal Bmal1 gene expression (A) and cAMP amount profile (B). Retinas were collected every 3 hours throughout the light-dark cycle after 3 days of STZ-induced diabetes: $n=3$ control and $n=3$ diabetic rat retinas per time point. Two-way ANOVA followed by Bonferroni's multiple-comparison posttest: (A) $P<0.0001$ for the treatment factor, $P<0.0001$ for the ZT factor, and $P<0.0001$ for the interaction. (B) $P<0.0001$ for the treatment factor, $P<0.0001$ for the ZT factor and $P<0.0005$ for the interaction. ${ }^{* *} P<0.001$, ${ }^{* * *} P<0.0001 \mathrm{vs}$. control, plotted as the mean \pm SEM.

in control rats. Thus, the AANAT activity peak found at ZT15 supports the melatonin synthesis peaks observed at ZT18 and -21 in INS-treated animals. Reinforcing our data, Lynch et al. ${ }^{52}$ showed that insulin was able to increase pineal AANAT activity and consequently plasma levels of melatonin. The same was observed by Peschke et al. ${ }^{51}$ in Goto Kakizaki rats with spontaneous diabetes. Moreover, Garcia et al. ${ }^{34}$ and Peliciari-Garcia et al. ${ }^{35}$ demonstrated, in vitro, that insulin is able to potentiate the norepinephrine-induced melatonin synthesis in the rat pineal gland via phosphatidylinositol-3 kinase (PI3K) signaling and AANAT activity.

It is known that the BMAL1:CLOCK complex is involved in AC1 and Aanat gene expression regulation and the cAMP signaling pathway is crucial for AANAT stability. Our data show high Bmal1 gene expression in the middle of the day (ZT6) and at ZT12, -15, and -18 in the control group. This multipeaked control profile is probably due to the measurement of Bmal1 mRNA levels in the whole retina, not just in the melatonin-synthesizing cells. The retina is a multilayered tissue that contains different cell types, and Bmall expression has been detected in the photoreceptors, the inner nuclear layer, and the ganglion cell layer. ${ }^{53}$

In the diabetic retinas, the variation in the daily expression of Bmal1 was lost in comparison with that in the control retinas, leading us to suppose that this flattened Bmal1 expression could impair the AC1 levels, resulting in the observed decrease in CAMP level and consequent AANAT activity reduction at ZT15. Moreover, Aanat gene expression may also be affected by the flattened Bmall expression contributing to the arrhythmic AANAT activity and reduction observed (Fig. 7).

Recent data from the literature suggest that both Clock and Bmal1 participate in the regulation of energy metabo- lism. ${ }^{54}$ Young et al. ${ }^{55}$ showed that STZ-induced diabetes is associated with alterations in the circadian clock of the rat heart. Further experiments are under way to evaluate cAMP decline and how the retinal circadian clock is affected by diabetes.

There are no data in the literature that show the effects of diabetes on the retinal melatonin synthesis pathway. On the other hand, it has been reported that retinal insulin signaling is in a constitutively higher steady state and that the basal phosphorylation and activity of the insulin receptor and serine/ threonine protein kinase (Akt) maintain a tonic cell-survival signal in the metabolically active retina. ${ }^{56}$ Diabetes induced by STZ treatment gives rise to late neural cell death in the retina, but it is has not been established yet whether this effect is directly related to reduced circulating insulin, or the reduction of insulin increases apoptosis by an indirect mechanism such as hyperglycemia. ${ }^{57}$ Considering our results, we do not know whether there is a direct action of insulin in the retinal melatonin synthesis pathway, or the effect is caused by hyperglycemia, or both factors contribute. Insulin treatment prevented a reduction in melatonin synthesis, but it also controlled the hyperglycemia.

Although additional studies are necessary to clarify the mechanisms underlying the decreased insulin and consequent hyperglycemia involvement in the retinal melatonin synthesis impairment, it is important to note that the melatonin synthesis reduction already reported in the pineal gland of STZ-induced diabetic rats is also observed in a local melatonin tissue synthesizer, the retina.

In this way, in the presence of diabetes, the reduction of local melatonin synthesis, a powerful natural antioxidant, may contribute, in addition to the well-known impairment
A

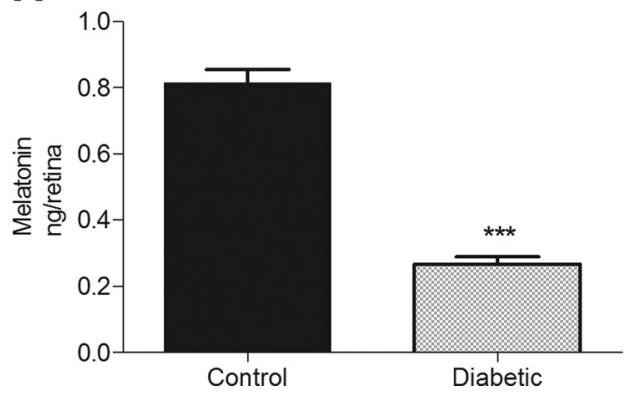

B

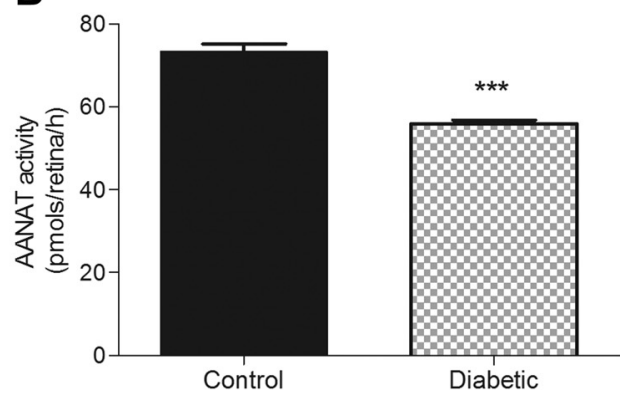

Figure 6. Retinal melatonin (A) and AANAT activity (B) from control and 15 days STZ-induced diabetic rats. Retinas were collected at ZT18, $n=10$. Two-tailed Student's $t$-test, **: $P<0.0001$ vs. control, plotted as the mean \pm SEM. 


\section{Darkness}

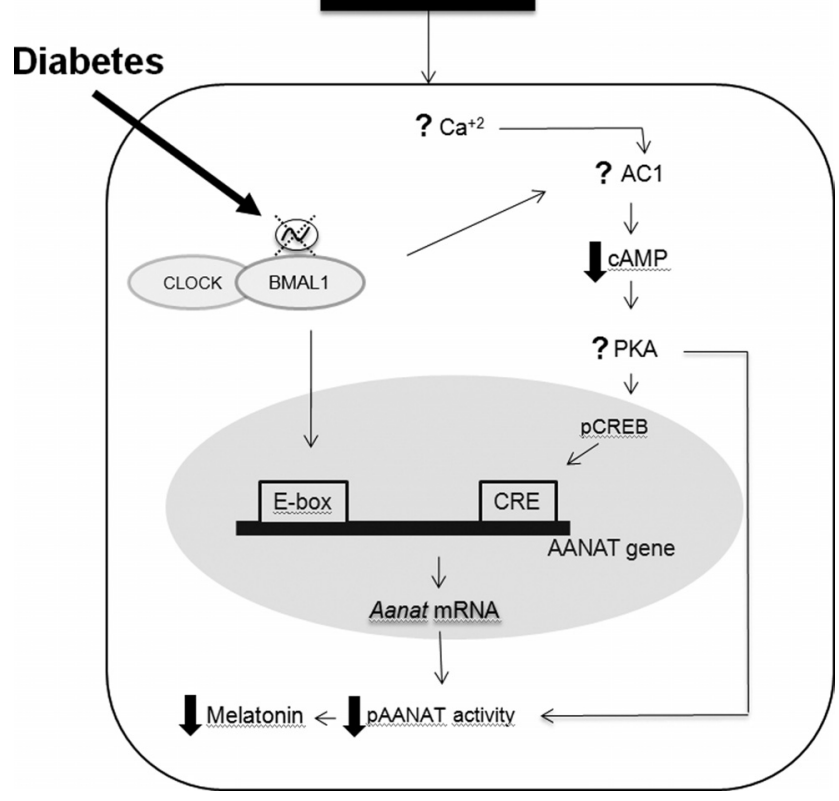

FIGURE 7. The potential mechanism involved in the retinal melatonin synthesis impairment induced by diabetes. In the diabetic condition, we observed a flattened Bmal1 gene expression, a reduction of cAMP content and, consequently, a reduction on the AANAT activity and melatonin amount. Thick arrows: the consequences of STZ-induced diabetes.

in retinal antioxidant defense, to the development of diabetic retinopathy, a frequent complication of this disease.

\section{Acknowledgments}

The authors thank Julieta Helena Scialfa for technical support.

\section{References}

1. Tosini G, Menaker M. The clock in the mouse retina: melatonin synthesis and photoreceptor degeneration. Brain Res. 1998;789: 221-228.

2. Pang SF, Yu HS, Suen HC, Brown GM. Melatonin in the retina of rats: a diurnal rhythm. J Endocrinol. 1980;87:89-93.

3. Ivanova TN, Iuvone PM. Melatonin synthesis in retina: circadian regulation of arylalkylamine $\mathrm{N}$-acetyltransferase activity in cultured photoreceptor cells of embryonic chicken retina. Brain Res. 2003; 973:56-63.

4. Gauer F, Craft CM. Circadian regulation of hydroxyindole-O-meth yltransferase mRNA levels in rat pineal and retina. Brain Res. 1996;737:99-109.

5. Sakamoto K, Ishida N. Circadian expression of serotonin N-acetyltransferase mRNA in the rat retina. Neurosci Lett. 1998;245:113116.

6. Chong NW, Cassone VM, Bernard M, Klein DC, Iuvone PM. Circadian expression of tryptophan hydroxylase mRNA in the chicken retina. Brain Res Mol Brain Res. 1998;61:243-250.

7. Green CB, Besharse JC. Tryptophan hydroxylase expression is regulated by a circadian clock in Xenopus laevis retina. $J$ Neurochem. 1994;62:2420-2428.

8. Fukuhara C, Liu C, Ivanova TN, et al. Gating of the cAMP signaling cascade and melatonin synthesis by the circadian clock in mammalian retina. J Neurosci. 2004;24:1803-1811.

9. Niki T, Hamada T, Ohtomi M, et al. The localization of the site of arylalkylamine $\mathrm{N}$-acetyltransferase circadian expression in the photoreceptor cells of mammalian retina. Biochem Biophys Res Com mun. 1998;248:115-120.
10. Baler R, Covington S, Klein DC. The rat arylalkylamine N-acetyltransferase gene promoter. cAMP activation via a cAMP-responsive element-CCAAT complex. J Biol Chem. 1997;272:6979-6985.

11. Iuvone $\mathrm{PM}$, Brown $\mathrm{AD}$, Haque $\mathrm{R}$, et al. Retinal melatonin production: role of proteasomal proteolysis in circadian and photic control of arylalkylamine N-acetyltransferase. Invest Ophthalmol Vis Sci. 2002;43:564-572.

12. Chen W, Baler R. The rat arylalkylamine N-acetyltransferase E-box: differential use in a master vs. a slave oscillator. Brain Res Mol Brain Res. 2000;81:43-50.

13. LaVail MM. Rod outer segment disk shedding in rat retina: relationship to cyclic lighting. Science. 1976;194:1071-1074.

14. Walker JA, Olton DS. Circadian rhythm of luminance detectability in the rat. Physiol Behav. 1979;23:17-21.

15. Doyle SE, McIvor WE, Menaker M. Circadian rhythmicity in dopamine content of mammalian retina: role of the photoreceptors. J Neurochem. 2002;83:211-219.

16. Brandenburg J, Bobbert AC, Eggelmeyer F. Circadian changes in the response of the rabbits retina to flashes. Behav Brain Res. 1983;7:113-123

17. Dmitriev AV, Mangel SC. Circadian clock regulation of $\mathrm{pH}$ in the rabbit retina. J Neurosci. 2001;21:2897-2902.

18. Boyd TA, McLeod LE. Circadian rhythms of plasma corticoid levels, intraocular pressure and aqueous outflow facility in normal and glaucomatous eyes. Ann N Y Acad Sci. 1964;117:597-613.

19. Manglapus MK, Iuvone PM, Underwood H, Pierce ME, Barlow RB. Dopamine mediates circadian rhythms of rod-cone dominance in the Japanese quail retina. J Neurosci. 1999;19:4132-4141.

20. Green CB, Besharse JC. Retinal circadian clocks and control of retinal physiology. J Biol Rhythms. 2004;19:91-102.

21. Pierce ME, Besharse JC. Circadian regulation of retinomotor movements, I: interaction of melatonin and dopamine in the control of cone length. J Gen Physiol. 1985;86:671-689.

22. Bartell PA, Miranda-Anaya M, McIvor W, Menaker M. Interactions between dopamine and melatonin organize circadian rhythmicity in the retina of the green iguana. J Biol Rhythms. 2007;22:515523.

23. Reiter RJ, Tan DX, Cabrera J, et al. The oxidant/antioxidant network: role of melatonin. Biol Signals Recept. 1999;8:56-63.

24. Baydas G, Tuzcu M, Yasar A, Baydas B. Early changes in glial reactivity and lipid peroxidation in diabetic rat retina: effects of melatonin. Acta Diabetol. 2004;41:123-128.

25. Reiter RJ, Acuna-Castroviejo D, Tan DX, Burkhardt S. Free radicalmediated molecular damage: mechanisms for the protective actions of melatonin in the central nervous system. Ann N Y Acad Sci. 2001;939:200-215.

26. Gül M, Emre S, Esrefoglu M, Vard N. Protective effects of melatonin and aminoguanidine on the cornea in streptozotocin-induced diabetic rats. Cornea. 2008;27:795-801.

27. Osborne NN, Nash MS, Wood JP. Melatonin counteracts ischemiainduced apoptosis in human retinal pigment epithelial cells. Invest Ophthalmol Vis Sci. 1998;39:2374-2383.

28. Silva SO, Rodrigues MR, Carvalho SR, Catalani LH, Campa A, Ximenes VF. Oxidation of melatonin and its catabolites, N1acetyl-N2 -formyl-5-methoxykynuramine and N1-acetyl-5methoxykynuramine, by activated leukocytes. J Pineal Res. 2004;37:171-175.

29. Guenther AL, Schmidt SI, Laatsch H, et al. Reactions of the melatonin metabolite AMK (N1-acetyl-5-methoxykynuramine) with reactive nitrogen species: formation of novel compounds, 3-acetamidomethyl-6-methoxycinnolinone and 3-nitro-AMK. J Pineal Res. 2005;39:251-260.

30. Baydas G, Ercel E, Canatan H, Donder E, Akyol A. Effect of melatonin on oxidative status of rat brain, liver and kidney tissues under constant light exposure. Cell Biochem Funct. 2001;19:37-41.

31. Obrosova IG, Fathallah L, Greene DA. Early changes in lipid peroxidation and antioxidative defense in diabetic rat retina: effect of DL-alpha-lipoic acid. Eur J Pharmacol. 2000;398:139-146.

32. Lima FB, Machado UF, Bartol I, et al. Pinealectomy causes glucose intolerance and decreases adipose cell responsiveness to insulin in rats. Am J Physiol. 1998;275:E934-E941. 
33. Anhe GF, Caperuto LC, Pereira-Da-Silva M, et al. In vivo activation of insulin receptor tyrosine kinase by melatonin in the rat hypothalamus. J Neurochem. 2004;90:559-566.

34. Garcia RA, Afeche SC, Scialfa JH, et al. Insulin modulates norepinephrine-mediated melatonin synthesis in cultured rat pineal gland. Life Sci. 2008;82:108-114.

35. Peliciari-Garcia RA, Marcal AC, Silva JA, et al. Insulin temporal sensitivity and its signaling pathway in the rat pineal gland. Life Sci. 2010;87:169-174.

36. Freitas HS, D'Agord Schaan B, da Silva RS, Okamoto MM, OliveiraSouza M, Machado UF. Insulin but not phlorizin treatment induces a transient increase in GLUT2 gene expression in the kidney of diabetic rats. Nephron Physiol. 2007;105:42-51.

37. Martins E Jr, Fernandes LC, Bartol I, Cipolla-Neto J, Costa Rosa LF The effect of melatonin chronic treatment upon macrophage and lymphocyte metabolism and function in Walker-256 tumour-bearing rats. J Neuroimmunol. 1998;82:81-89.

38. Cipolla-Neto J, Bartol I, Seraphim PM, Afeche SC, Scialfa JH, Peracoli AM. The effects of lesions of the thalamic intergeniculate leaflet on the pineal metabolism. Brain Res. 1995;691:133-141.

39. Parfitt A, Weller JL, Klein DC, Sakai KK, Marks BH. Blockade by ouabain or elevated potassium ion concentration of the adrenergic and adenosine cyclic 3',5'-monophosphate-induced stimulation of pineal serotonin N-acetyltransferase activity. Mol Pharmacol. 1975;11:241-255.

40. Deguchi T, Axelrod J. Sensitive assay for serotonin N-acetyltransferase activity in rat pineal. Anal Biochem. 1972;50:174-179.

41. Nicoletti I, Migliorati G, Pagliacci MC, Grignani F, Riccardi C. A rapid and simple method for measuring thymocyte apoptosis by propidium iodide staining and flow cytometry. I Immunol Methods. 1991;139:271-279.

42. Vandesompele J, De Preter K, Pattyn F, et al. Accurate normalization of real-time quantitative RT-PCR data by geometric averaging of multiple internal control genes. Genome Biol. 2002;3: RESEARCH0034.

43. Colantuoni A, Longoni B, Marchiafava PL. Retinal photoreceptors of Syrian hamsters undergo oxidative stress during streptozotocininduced diabetes. Diabetologia. 2002;45:121-124.

44. Park SH, Park JW, Park SJ, et al. Apoptotic death of photoreceptors in the streptozotocin-induced diabetic rat retina. Diabetologia. 2003; $46: 1260-1268$.

45. Pang SF, Tang F, Tang PL. Alloxan-induced diabetes and the pineal gland: differential effects on the levels of pineal $\mathrm{N}$ - acetylserotonin, pineal melatonin, and serum melatonin. $J \mathrm{Pi}$ neal Res. 1985;2:79-85.

46. Stebelova K, Herichova I, Zeman M. Diabetes induces changes in melatonin concentrations in peripheral tissues of rat. Neuroendocrinol Lett. 2007;28:159-165.

47. Champney TH, Brainard GC, Richardson BA, Reiter RJ. Experimentally-induced diabetes reduces nocturnal pineal melatonin content in the Syrian hamster. Comp Biochem Pbysiol A Comp Pbysiol. 1983;76:199-201.

48. Champney TH, Holtorf AP, Craft CM, Reiter RJ. Hormonal modulation of pineal melatonin synthesis in rats and Syrian hamsters: effects of streptozotocin-induced diabetes and insulin injections. Comp Biochem Physiol A Comp Pbysiol. 1986;83:391-395.

49. O'Brien IA, Lewin IG, O'Hare JP, Arendt J, Corrall RJ. Abnormal circadian rhythm of melatonin in diabetic autonomic neuropathy. Clin Endocrinol. 1986;24:359-364.

50. Tutuncu NB, Batur MK, Yildirir A, et al. Melatonin levels decrease in type 2 diabetic patients with cardiac autonomic neuropathy. $J$ Pineal Res. 2005;39:43-49.

51. Peschke E, Frese T, Chankiewitz E, et al. Diabetic Goto Kakizaki rats as well as type 2 diabetic patients show a decreased diurnal serum melatonin level and an increased pancreatic melatoninreceptor status. J Pineal Res. 2006;40:135-143.

52. Lynch HJ, Eng JP, Wurtman RJ. Control of pineal indole biosynthesis by changes in sympathetic tone caused by factors other than environmental lighting. Proc Natl Acad Sci U S A. 1973;70:17041707.

53. Gekakis N, Staknis D, Nguyen HB, et al. Role of the CLOCK protein in the mammalian circadian mechanism. Science. 1998;280:15641569.

54. Rudic RD, McNamara P, Curtis AM, et al. BMAL1 and CLOCK, two essential components of the circadian clock, are involved in glucose homeostasis. PLoS Biol. 2004;2:e377.

55. Young ME, Wilson CR, Razeghi P, Guthrie PH, Taegtmeyer H. Alterations of the circadian clock in the heart by streptozotocininduced diabetes. J Mol Cell Cardiol. 2002;34:223-231.

56. Reiter CE, Sandirasegarane L, Wolpert EB, et al. Characterization of insulin signaling in rat retina in vivo and ex vivo. Am J Pbysiol Endocrinol Metab. 2003;285:E763-E774.

57. Barber AJ, Lieth E, Khin SA, Antonetti DA, Buchanan AG, Gardner TW. Neural apoptosis in the retina during experimental and human diabetes: early onset and effect of insulin. J Clin Invest. 1998;102:783-791 